Revista Eletrônica de Direito Processual - REDP

Rio de Janeiro. Ano 15. Volume 22. Número 1. Janeiro a Abril de 2021

Periódico Quadrimestral da Pós-Graduação Stricto Sensu em Direito Processual da UERJ

Patrono: José Carlos Barbosa Moreira (in mem.). ISSN 1982-7636. pp. 752-780

www.redp.uerj.br

\title{
ANÁLISIS DEL MARCO JURÍDICO PENAL DE JUSTICIA RESTAURATIVA EN \\ MÉXICO Y PANAMÁ: UN ENFOQUE INTEGRAL SOBRE SU IMPERIOSA \\ ARMONIZACIÓN ${ }^{510}$
}

\section{ANALISYS OF THE CRIMINAL RULES OF RESTORATIVE JUSTICE IN MEXICO AND PANAMA: AN OVERVIEW THROUGH ITS IMPERIOUS HARMONIZATION}

Yulisán Fernández Silva

Doctorando en MASC por la Universidad Autónoma de Nuevo León, México. Máster en Criminología por la Universidad de la Habana, Cuba. Profesor de Derecho Penal, y Cultura de Paz por la Universidad Autónoma de Nuevo León. México. Email: fedezyulisan@gmail.com._https://orcid.org/0000-0002-91456075

Jazmín Flores-Montes

Doctoranda en MASC por la Universidad Autónoma de Nuevo León, México. Máster en Derecho Constitucional y Gobernabilidad. Miembro Activa de la RED Universitaria de Promoción de Derechos Humanos de la UANL. México. Email: jazmin_7_7@hotmail.com. https://orcid.org/0000-0001-81976782.

RESUMEN: El artículo analiza la construcción normativa, en el ámbito penal, de la JR en México y Panamá con el propósito de detectar áreas de perfeccionamiento proclives a la articulación de un modelo procesal integral y armónico en las normativas de estas naciones. Se toma como referencia las normativas procesales para adolescentes, las leyes especiales de

\footnotetext{
${ }^{510}$ Artigo recebido em 01/12/2020, sob dispensa de revisão.
} 
Métodos de Solución de Conflictos, y los procedimientos referentes a la fase de ejecución penal.

PALABRAS ClAVE: Justicia restaurativa. Armonización. Métodos de Solución de Conflictos. Derecho Procesal Penal.

ABSTRACT: The article aims to analyze the construction of rules, in criminal justice, concerning restorative justice in Mexico and Panama in order to identify areas of development towards an integral procedural model embracing those national rules. It takes into consideration the procedural rules concerning teenagers, the special rules concerning Alternative Dispute Resolution as well as the proceedings related to the criminal execution phase.

KEY WORDS: Restorative Justice. Harmonization. Alternative Dispute Resolution. Criminal procedural law.

\section{Consideraciones iniciales}

La forma en que es percibida la Justicia Restaurativa -en lo adelante JR - actualmente, como un proceso o programa dentro del sistema de enjuiciamiento penal ${ }^{511}$, y su divagación existente al estar dispersa entre diversas normativas y principios legales de los Estados mexicano y panameño, provoca que esta no sea observada como el nuevo paradigma de justicia humana. Esto dificulta que cobre vida propia y pueda desarrollarse a la par del modelo tradicional adversarial, limitando las herramientas en las que puede apoyarse y su aceptación como un nuevo cimiento de la justicia, con grandes beneficios sobre sus participantes, entre ellos, la generación de condiciones óptimas para el infractor hacia su posible reintegración social; y

\footnotetext{
${ }^{511}$ La Justicia Tradicional, es la que, siendo de cualquiera de las materias del Derecho que admite el juicio, se acude a los Tribunales para que las partes versen, donde uno sale ganador y el otro vencedor, y en este caso de la Justicia Penal, es mediante una sanción punible en la mayoría de los casos privativa de libertad hacia una de las partes, y sobre la otra la simulación de obtención de justicia.
} 
además, el apoyo a la víctima hacia la recuperación de su dignidad, sentimiento de seguridad, y aptitudes de pertenencia en una comunidad.

En ese sentido, las bondades del enfoque restaurativo tienen una connotación relevante en las formas de resarcimiento del daño, puesto que estas metodologías profundizan en aspectos psicológicos y sociológicos para identificar las inquietudes y necesidades de los sujetos que resultan afectados, de manera directa o indirecta, por la comisión de un hecho delictivo. Luego, la Justicia Restaurativa es una herramienta que genera condiciones favorables para la intervención no solo de las víctimas e infractores, sino también con la confluencia de familiares, vecinos cercanos, operadores del Sistema de Justicia y a la comunidad en general. Esta invitación a la participación de los diferentes actores de una forma u otra coadyuva a que se reconozca que existe un conflicto, del cual hay que responsabilizarse, e impulsar alternativas viables para reparar el daño causado, que pueden contribuir a lograr la reconciliación y el perdón visto como un sentimiento genuino de compasión ${ }^{512}$.

A su vez, la flexibilidad que proyectan los programas y prácticas de contenido restaurativo, han propiciado su adaptación a diversos modelos de justicia en el continente americano, impulsándose su instrumentalización desde las legislaciones procesales, también en leyes de desarrollo en materia de justicia alternativa, o inclusive como un dispositivo más de los mecanismos no adversariales de solución de controversias. Lo anterior ha resultado posible, debido a que, desde esta corriente pacífica de gestión de conflictos, se propugna una justicia más participativa, analizando las causas que ocasionaron el hecho criminal e incorporando una metodología adecuada para resolverlo a través de la colaboración de los involucrados.

No obstante, la diversidad de aplicación del paradigma restaurativo en los distintos modelos de ejercicio también ha provocado una distorsión, identificándose en algunas normativas con la mediación y la conciliación, dentro de una misma denominación, lo que genera confusión sobre los fundamentos de su aplicación. Por otro lado, la carencia de uniformidad de criterios en las legislaciones procesales penales, o la propia ausencia de la JR en las normativas jurídicas, impide la consolidación de un modelo pacificador y colaborativo

\footnotetext{
${ }^{512}$ GOJÓN MEZ GÓMEZ, Gabriel de Jesús \& VILLEDA, Brenda Judith. "Justicia restaurativa, una herramienta de paz en la resolución de conflictos comunitarios". Caso Nuevo León. Política criminal, 13(25), 2018, p. 555.
} 
alejado del esquema adversarial. En ese sentido, se analiza la construcción normativa, en el ámbito penal, de la JR en México y Panamá con el propósito de detectar áreas de perfeccionamiento proclives a la articulación de un modelo procesal integral y armónico en las normativas de estas naciones. Se toma como referencia las normativas procesales para adolescentes, las leyes especiales de Métodos de Solución de Conflictos ${ }^{513}$, y los procedimientos referentes a la fase de ejecución penal.

\section{2. ¿Dónde ubicar la Justicia Restaurativa?}

Un aspecto que ha generado gran debate tiene que ver con los fundamentos jurídicos de la JR, postulándose dos vertientes que perfilan un enfoque comparativo sobre la forma de implementar estas metodologías: como mecanismo o proceso; y como programa.

En apoyo a la primera tesis, la denominación del mecanismo, a los procesos restaurativos, responde a que se encuentran vinculada a un modelo jurídico concreto, y buscan su aplicación a través de marcos legales estrechos que le confieren operatividad. Desde esa óptica, el proceso se entiende como la participación conjunta de víctima, victimario, facilitador y comunidad para resolver las cuestiones derivadas del delito, buscando como resultado el acuerdo reparatorio que responda a las necesidades individuales y colectivas. En este sentido, la intervención de la JR no puede supeditarse a un esquema procesal, considerando que sus postulados no solo contemplan la participación y acercamiento de las partes a conocer las causas del conflicto, sino que, también se constata el impacto emocional reflejado en la víctima, como factor sensibilizador en el infractor que le impulsa a responsabilizarse con el hecho y reparar el daño.

De manera que, los posibles pasos, o fases, que pueden desarrollarse desde el enfoque restaurativo, no pueden considerarse actos procesales, puesto que estos no encuentran fundamento en la actividad jurisdiccional ${ }^{514}$, sino en la colaboración de las partes. Tampoco

\footnotetext{
${ }^{513}$ Sobre esta denominación coinciden los autores con el criterio del Doctor Francisco Javier Gorjón Gómez, en cuanto a que la configuración legal de Métodos de Solución de Conflictos no debe considerarse una vía alternativa, sino que debe constituir la primera fórmula para resolver los conflictos, dejando la alternancia al modelo tradicional adversarial.

${ }^{514}$ FERnÁNDEZ Pereira, Julio A. Temas para el estudio del Derecho Procesal Penal. Parte I. La Habana: Editorial Félix Varela, 2002, p.138.
} 
puede considerarse la JR como un mecanismo, considerando que va mucho más allá de la intervención de dos personas auxiliadas por un mediador o conciliador en función de lograr un acuerdo provechoso para los involucrados. En la JR se busca involucrar a la comunidad en la solución del conflicto, proyectando un efecto expansivo hacia el reforzamiento del tejido social.

Por otro lado, una segunda postura, avalada por la ONU, define la JR como un programa, que integra cualquier esquema procesal que utilice e intente lograr resultados restaurativos ${ }^{515}$ Sobre este tópico, cabe señalar que resulta frágil la tesis que designa la JR como un modelo o un programa ${ }^{516}$, puesto que esta metodología contempla un grupo de principios y valores como el respeto, encuentro, reparación, responsabilidad, seguridad, curación, reintegración y empatía ${ }^{517}$, que tienen una connotación diferente en cada país o región donde se implementa. De ahí que, no pueda representarse como un modelo único o ideal. Tampoco es saludable, incorporarle como un atributo general, el término de comunitaria, considerando que el área de aplicación de los procesos restaurativos habilita otros ámbitos en los que, de igual modo tienen un impacto trascendental.

Dentro de este marco, coincidimos con la autora Domingo de la Fuente ${ }^{518}$ en considerar a la JR como "un marco filosófico o teoría jurídica — que impulsa el cambio de paradigma para responder al delito que se centra en el daño causado y en las acciones requeridas para enmendar este daño. Concordamos también, en que ciertamente, ..." se parte de la premisa que el crimen causa daños a las personas y a la comunidad, y que la justicia puede reparar esos daños, dándole participación a las partes en el proceso“.

Además, también se les da participación a otros sujetos afectados indirectamente por el delito, haciéndole ver al acusado las consecuencias de sus actos, y motivándole a reconocer su participación, así como, reparar el daño causado, acciones estas que gravitan dentro de un grupo

\footnotetext{
515 BRITTO RUIZ, Diana. JUSTICIA RESTAURATIVA: Reflexiones sobre la Experiencia de Colombia. Loja: Universidad Técnica Particular de la Loja. 201, 2010, p. 33.

516 DOMINGO DE LA FUENTE, Virginia. "Justicia restaurativa como ciencia penal o social, encaminada a mejorar la justicia. Educación Social”. Revista d'Intervenció Socioeducativa (67), 73-90, 2017, p.76

517 Albertí i CORTÉS, M. \& PEDROL LliRINÓS, M. "El enfoque restaurativo en el ámbito educativo. Cuando innovar en la escuela. Educación Social”. Revista d'Intervenció Socioeducativa, 47-72, 2017, p.56

518 DOMINGO DE LA FUENTE, Virginia. “Justicia restaurativa..”, Op.cit., p.79
} 
de metodologías que propician su materialización, y que pueden denominarse procesos, programas o prácticas según su contenido.

\section{La Justicia Restaurativa ni es abolicionismo penal, ni supone privatización del Modelo de Justicia criminal}

La convergencia de los postulados de la JR y las del abolicionismo penal, ha sido objeto de debate por los autores que defienden la desaprobación del derecho penal como instrumento de control social y la expropiación del conflicto al Estado, a fin de devolverles a las partes en disputa, la posibilidad de alcanzar un acuerdo entre ellas, a través del diálogo ${ }^{519}$.

Los abolicionistas son partidarios de eliminar el castigo para reprimir a una persona acusada y condenada por la comisión de un delito, y se oponen a la consolidación de la ley penal como medio de control social. Estos tratadistas sostienen, que el modelo de justicia penal tradicional causa más perjuicios que beneficios a la comunidad, y que el castigo, no es un medio adecuado para reaccionar frente a un ilícito penal, y, por mejor que se pueda utilizar, es un orden social injusto, selectivo y estigmatizante ${ }^{520}$. Esta visión, partidaria de la revocación ius puniendi, entiende que el modelo penal debe ser reemplazado por mecanismos descentralizados de gestión de controversias, considerando que los tribunales no son escenarios idóneos para ventilar conflictos interpersonales, debiendo gestionarse desde la esfera privada y con la participación de los involucrados.

Desde esta perspectiva la JR, puede representarse como un dispositivo viable para la descentralización del conflicto y devolverles a las partes la posibilidad de sanear sus relaciones centrándose en la reparación del año, y la responsabilización del ofensor por la conducta realizada. Lo anterior supone, según esta corriente, que el enfoque restaurativo tiene una orientación y propósito, similares a las teorías abolicionistas.

\footnotetext{
${ }^{519}$ LlOBET RodríGueZ, J. Justicia Restaurativa y la Protección de la Víctima. Libro en Homenaje a Julio Maier, , 2005, pp. 873-874.

520 ACHUTTI, Daniel. "Abolicionismo penal y justicia restaurativa: del idealismo al realismo políticocriminal". Revista de Derechos Humanos y Estudios Sociales, Año VII(13), 2015, p.56.
} 
Sin embargo, si bien es cierto que las metodologías restaurativas ofrecen una visión distinta al clima adversarial, al preponderar la reparación sobre el castigo; ello no significa una ruptura o negación de la potestad del Estado y su sistema legal actual. En el mismo sentido, la JR tampoco puede considerarse un modelo que negocia penas, ni genera impunidad, mucho menos agravar la situación de los involucrados, ni en lo procesal ni en lo personal, puesto que su perfil deontológico se opone a ello. Es decir, la JR busca desburocratizar la administración de justicia, y consolidar las modalidades de solución pacífica de controversias, sin renunciar a la función social ${ }^{521}$.

Por consiguiente, la introducción del paradigma restaurativo acentúa la concepción garantista sobre un "derecho penal mínimo. ${ }^{-522}$, considerando que la ausencia de un derecho penal como instrumento de control social, generaría una anarquía punitiva, es decir, el libre abandono del sistema social y una reacción salvaje incontrolada contra las ofensas, con un inevitable predominio del más fuerte ${ }^{523}$.

\section{Análisis sobre tratamiento jurídico del enfoque restaurativo en la legislación federal de México}

La reforma constitucional del año 2008 en México, en materia de justicia y seguridad, configuró un modelo jurídico binomial en el que convergen dos esquemas procesales de solución de conflictos: el sistema tradicional adversarial y el modelo de justicia alternativa; este último, propugna la articulación de nuevas figuras de gestión pacífica de conflictos entre las que se incluyen las metodologías restaurativas. Dicho lo anterior, la actualización del ordenamiento jurídico mexicano generó mayor presencia de los ciudadanos en la administración de justicia, a partir de la reorientación del derecho de acceso a la justicia hacia nuevas formas de solución de conflictos basadas en la autogestión y la comunicación pacífica.

\footnotetext{
${ }^{521}$ DíAZ MADRIGAL, I. N. La mediación en el sistema de justicia penal: justicia restaurativa en México y España. Serie Juicios Orales. núm. 9. México, D.F, 2016, p. 45.

${ }^{522}$ FERRAJOLI, Luigi. "El derecho penal mínimo". Poder y control, vol. 10, 1986, p.16

${ }^{523}$ Cfr.FerRaJOLI, Luigi. "El derecho penal mínimo"... Op, cit., p. 17.
} 
Esta misma reforma incorporó nuevos dispositivos constitucionales, que transformaron el esquema rígido instaurado hasta ese momento, en ese sentido, la reforma al artículo 17, párrafo cuarto, en el texto constitucional, se considera el epicentro regulatorio de los MSC, y el fundamento de la justicia alternativa ${ }^{524}$. También resultó fundamental la incorporación de los numerales 18, sexto párrafo, 73 fracciones XXI c) y XXIX a), esto propició la unificación del sistema de justicia penal, con la recomendación de una legislación procesal única en el marco penal de los adultos, y el de adolescentes; además de una disposición jurídica universal sobre los MSC. Lo anterior se traduce en un efecto armonizador en todo el país, ya que concederle al legislador la posibilidad de crear una ley servirá de referencia y marco regulatorio a nivel federal, estatal y local ${ }^{525}$.

Sin embargo, en materia JR, no existe un a regulación homogénea en la república mexicana, en virtud de que la reforma constitucional estuvo perfilada a la consolidación del esquema procesal de justicia alternativa, a través de los MSC, como vía fundamental, sin que existiera en ese momento una definición o conceptualización de los dispositivos viables, aspecto que se esclareció en las leyes orgánicas. Y si bien es cierto, que existe una profusión importante de leyes promulgadas que entraron en vigor con posterioridad, estas no regulan de manera uniforme lo relacionado con la JR y sus metodologías de intervención, provocando que en algunas ocasiones exista distorsión en la denominación legal y en las definiciones conceptuales.

\subsection{La Ley Nacional de Mecanismos Alternativos de Solución de Controversias en Materia Penal}

Como ya se mencionó, el enfoque restaurativo en México se visualiza con una proyección indistinta en las diversas legislaciones nacionales del ámbito penal, con el propósito de abarcar todas las etapas del proceso criminal.

En este sentido, la promulgación de Ley Nacional de Mecanismos Alternativos de Solución de Controversias en Materia Penal—en lo adelante LNMASCMP—, promulgada 29

\footnotetext{
${ }^{524}$ SÁNCHEZ GARCíA, Arnulfo. Esquemas de mediación y arbitraje, Tirant lo blanch, México, 2019, p. 109.

525 SÁNCHEZ GARCÍA, Arnulfo; FERnÁndeZ Silva, Yulisán. El interés superior del menor en el marco de la utilización de los métodos alternos de solución de conflictos en el ámbito penal. Actualidad jurídica iberoamericana, 2020, no 13, p. 815.
} 
Revista Eletrônica de Direito Processual - REDP

Rio de Janeiro. Ano 15. Volume 22. Número 1. Janeiro a Abril de 2021

Periódico Quadrimestral da Pós-Graduação Stricto Sensu em Direito Processual da UERJ

Patrono: José Carlos Barbosa Moreira (in mem.). ISSN 1982-7636. pp. 752-780

www.redp.uerj.br

de diciembre de 2014, ha venido a clarificar los aspectos relacionados con los principios, definiciones, y reglas generales de los MSC, refrendados en la ley fundamental. Sin embargo, en materia de JR, se vislumbra un área de oportunidad, que requiere de un estudio para postular las bases de una restructuración normativa incorporando en esta, el enfoque restaurativo.

En primer orden, la LNMASCMP adolece de una conceptualización diáfana sobre JR, lo que dificulta en mayor medida definir los fundamentos teóricos de la institución, a fin de propiciar una instrumentalización adecuada, máxime, cuando el ordenamiento procesal federal no clarifica la temática abordada. Estos aspectos, han sido contemplados con mayor claridad en las leyes de las entidades federativas, como el caso de Nuevo León, entidad que incorpora los MSC desde el año 2005, y que en su actual ordenamiento sobre justicia alternativa- Ley de Mecanismos Alternativos para la Solución de Controversias para el Estado Nuevo León, en lo adelante LMASCNL-, logra postular un concepto de Justicia Restaurativa ${ }^{526}$

Otro aspecto relevante del cuerpo legal de la entidad federal- artículo 24-, es que se apertura la posibilidad a las partes para que puedan elegir el tipo de proceso restaurativo y los MSC contemplados, para solucionar su disputa ${ }^{527}$; aunque, la reparación del daño en el ámbito penal queda fuera de la aplicación de esta ley, considerando que solo aplica para las controversias que se suscitan en materia familiar, civil, escolar y comunitaria.

Por su parte, la LNMASCMP, contempla dentro de las denominaciones recogidas en su texto como dispositivos no adversariales, a la mediación, la conciliación, y la Junta Restaurativa; este último sería el único de los procedimientos restaurativos reconocidos.

${ }^{526}$ LEY DE DE MECANISMOS ALTERNATIVOS PARA LA SOLUCIÓN DE CONTROVERSIAS PARA EL ESTADO DE NUEVO LÉON. (28 de JUNIO de 2017). PERIÓDICO OFICIAL DEL ESTADO. Recuperado el 23 de Mayo de 2020, de www.hcnl.gob.mx: http://www.hcnl.gob.mx/trabajo_legislativo/Ley dees/Ley dees/Leyde_de_mecanismos_alternativos_para_la_solucion_de_controversias_para_el_Estado_de_nuevo_leon/.: Fracción XV del artículo 2: Justicia Restaurativa: Mecanismo mediante el cual las partes de una controversia se involucran para identificar y atender colectivamente las consecuencias del hecho o conducta que se reclama y las necesidades y obligaciones de cada uno de los interesados a fin de resolver el conflicto, esto con el propósito de lograr la reintegración en la comunidad, la recomposición social, así como la reparación del daño o perjuicio causado, o ambos, en su caso.

${ }^{527}$ LEY DE DE MECANISMOS ALTERNATIVOS PARA LA SOLUCIÓN DE CONTROVERSIAS PARA EL ESTADO DE NUEVO LÉON... Op. cit., p.14. 
Revista Eletrônica de Direito Processual - REDP

Rio de Janeiro. Ano 15. Volume 22. Número 1. Janeiro a Abril de 2021

Periódico Quadrimestral da Pós-Graduação Stricto Sensu em Direito Processual da UERJ

Patrono: José Carlos Barbosa Moreira (in mem.). ISSN 1982-7636. pp. 752-780

www.redp.uerj.br

La designación de Junta Restaurativa resultó ser un nombre novedoso, interesante y de amplio contenido social ${ }^{528}$, ya que no solo involucra a los protagonistas del conflicto, sino posibilita la intervención de representantes de la comunidad a la que pertenecen, a efectos de fomentar la recomposición social. La denominación de Junta Restaurativa proviene del poder legislativo ${ }^{529}$, y representa una innovación nominal, considerando que virtualiza los objetivos tradicionales de la $\mathrm{JR}^{530}$.

Cabe señalar, que la Junta Restaurativa es el único mecanismo— así nombrado por la ley que distingue desde la propia conceptualización cuáles son los actores que podrán interactuar dentro del enfoque restaurativo, en este caso la víctima, el ofensor y además la comunidad ${ }^{531}$.Por lo que, la calificación de las personas plenamente identificadas sería uno de los criterios para remitir al proceso restaurativo, que continuaría con la valoración del resarcimiento del daño, desde una perspectiva integral.

Ahora bien, a pesar de concebirse la Junta, como un modelo de aplicación de la JR, no cumple totalmente esta finalidad, considerando que, se contempla dentro de la LNMASCMP como uno de los mecanismos alternos, y tal denominación distorsiona la naturaleza y alcance de este tipo de metodologías de intervención. La forma de materializarse es a través del acuerdo reparatorio que concentra las necesidades individuales y colectivas.

En este orden de ideas, la Junta Restaurativa - también nombrada en otros ordenamientos jurídicos como conferencias familiares, o grupales de comunidad y familia-, tiene por objetivo desarrollar entre todas las personas que participan, un plan para responder al delito, $\mathrm{y}$, sobre

\footnotetext{
528 Carlín Balboa, A. MANUAL BÁSICO DE JUSTICIA PARA ADOLESCENTES, México D.F, México: Poder Judicial del Estado de Nuevo León, 2018, p.65.

${ }^{529}$ GRAILlET GonZÁlEZ, Eleazar. DE LA JUNTA RESTAURATIVA. En VÁSQUEZ GÁNDARA, Carlos Antonio. LEY DE NACIONAL DE MECANISMOS ALTERNATIVOS DE SOLUCIÓN DE CONTROVERSIAS EN MATERIA PENAL COMENTADA (pág. 143), Veracruz: Universidad de Xalapa, 2015, p. 144.

${ }^{530}$ SÁNCHEZ GARCÍA, Arnulfo. ESQUEMAS DE MEDIACIÓN Y ARBITRAJE. Op. cit., p. 30.

${ }^{531}$ LEY DE NACIONAL DE MECANISMOS ALTERNATIVOS DE SOLUCIÓN DE CONTROVERSIAS EN MATERIA PENAL. (29 de Diciembre de 2014). Diario Oficial de la Federación. Recuperado el 22 de Mayo de 2020, de /www.diputados.gob.mx: http://www.diputados.gob.mx/Ley deesBiblio/pdf/LNMASCMP_291214.pdf. artículo 27: La Junta Restaurativa es el mecanismo mediante el cual la víctima u ofendido, el imputado y, en su caso, la comunidad afectada, en libre de ejercicio de su autonomía, buscan construyen opciones y proponer opciones de solución de controversia, con el objeto de lograr un acuerdo que atienda las necesidades y responsabilidades individuales y colectivas, así como la reintegración de la víctima u ofendido y del imputado a la comunidad y la recomposición del tejido social.
} 
Revista Eletrônica de Direito Processual - REDP

Rio de Janeiro. Ano 15. Volume 22. Número 1. Janeiro a Abril de 2021

Periódico Quadrimestral da Pós-Graduação Stricto Sensu em Direito Processual da UERJ

Patrono: José Carlos Barbosa Moreira (in mem.). ISSN 1982-7636. pp. 752-780

www.redp.uerj.br

todo, realiza una reparación, buscando mayor participación de la comunidad local, desde un entorno próximo a las partes y a la comunidad ${ }^{532}$.

Es decir, con la implementación de la Junta Restaurativa se busca enfatizar en la dimensión social de los delitos y conflictos, restaurar el lazo social dañado, a través de un proceso de reparación y reconciliación entre víctima y ofensor, con la participación de la comunidad $^{533}$. Luego, la utilización de los esquemas restaurativos, buscan más allá de la responsabilización y reinserción del infractor, además, su diseño no está enfocado a reducir la reincidencia; tampoco sus fundamentos teóricos están orientados únicamente a delitos leves u ofensores no reincidentes. Por ende, sus postulados también pueden aplicarse a conductas más graves, con la diferencia de que en los delitos de mayor entidad no actuarían como dispositivos que buscan la extinción de la acción penal, sino que representan un complemento- tampoco es un reemplazo al modelo tradicional vigente- al proceso penal, pudiendo emplearse en cualquier etapa del proceso, y ayudando a sanar a la víctima, y que el victimario logre responsabilizarse con sus acciones ${ }^{534}$.

Al analizar los aspectos mencionados, se advierten algunos desaciertos del modelo restaurativo que obra en la LNMASCMP. En primer orden, la propia configuración legal del artículo 27 de la normativa ${ }^{535}$, dispone que el objetivo fundamental de la Junta Restaurativa es la de lograr un acuerdo que podrá contener la satisfacción de las necesidades colectivas e individuales. Lo que nos lleva a colegir, que la materialización de estas necesidades, están reflejadas en el contenido del convenio. Este particular, se ve ratificado en la consecución de los apartados del cuerpo legal, reflejándose en la figura del facilitador quien deberá, concretar los aspectos del acuerdo especialmente en materia de reparación - en este caso el alcance de la reparación comprende el reconocimiento de responsabilidad y formulación de una disculpa, así

\footnotetext{
532 CHOYA FORÉS, Nastia. Prácticas restaurativas: círculos y conferencias. Recuperado el 23 de Mayo de 2020, de Sociedadvascavictimologia. org,: Http: //Sociedadvascavictimologia. org, 2015, p. 9. En CARNEVALI RODRÍGUEZ, Raúl. "La justicia restaurativa como mecanismo de solución de conflictos. Su examen desde el derecho penal”, Revista Justicia juris, 13(1), 2017, p. 124.

${ }^{53}$ BRITTO RuIZ, Diana. JUSTICIA RESTAURATIVA...Op cit., p. 22.

${ }^{534}$ Cfr.DOMINGO DE LA FUENTE, Virginia. “Justicia restaurativa”... Op,cit., p. 79.

${ }^{535}$ LEY DE NACIONAL DE MECANISMOS ALTERNATIVOS DE SOLUCIÓN DE CONTROVERSIAS EN MATERIA PENAL. (29 de Diciembre de 2014). Diario Oficial de la Federación. Recuperado el 22 de Mayo de 2020, de http://www.diputados.gob.mx/LeydeesBiblio/pdf/LNMASCMP_291214.pdf
} 
como el compromiso de no repetición de la conducta a través de programas o actividades que contribuyan evitar a la reincidencia en la conducta; y además, un plan de restitución que pueda ser económico o en especie-, lo que posibilitará a través de la ratificación del convenio, la extinción de la acción penal.

Lo anterior significa, que lo dispuesto en la Junta Restaurativa, deberá patentizarse en la suscripción del acuerdo, lo que impone una restricción a este proceso, en cuanto que, en el período de formulación de denuncia y antes de dictar el auto de apertura a juicio, solo podrá llevarse a cabo en las conductas delictivas previstas en autorizadas en la norma ${ }^{536}$ - $\mathrm{CNPP}$-art. 187, fracción I, II, III—, desnaturalizando los fundamentos teóricos de esta institución. Es decir, en los casos en que se pretenda lograr un acuerdo reparatorio, por medio de este modelo restaurativo, solo podrá realizarse - en la etapa investigativa - en delitos culposos, o delitos de carácter patrimonial sin violencia contra las personas, lo que sin dudas representa una limitante para modalidad restaurativa, al tener que regirse por la legislación procesal.

Otros aspectos que dificultan la instrumentación de la Junta Restaurativa, en la fase investigativa, es, que de acuerdo a su metodología este dispositivo requiere mayor preparación en la detección, armonización de los intereses y necesidades de las partes-el art.28 de la LNMASCMP aborda que el facilitador realizará sesiones preparatorias con cada uno de los intervinientes-, escenario que involucra otros actores como la comunidad, a partir de la connotación social que puede conllevar una actuación asertiva de los intervinientes ${ }^{537}$. Por tanto, es poco probable que los aspectos señalados puedan materializarse a través del acuerdo reparatorio, en el período de un mes que prevé la legislación procesal federal para la fase indagatoria. De ahí que, en la práctica las autoridades prioricen su aplicación en la fase de ejecución penal, quedando latente la modificación del término previsto en el período investigativo, buscando optimizar la función judicial.

${ }^{536}$ Código Nacional de Procedimientos Penales. Diario Oficial de la Federación. Recuperado el 26 mayo de 2020, de http://www.diputados.gob.mx/LeyesBiblio/pdf/CNPP_220120.pdf , 2014.

${ }^{537}$ LEY DE NACIONAL DE MECANISMOS ALTERNATIVOS DE SOLUCIÓN DE CONTROVERSIAS EN MATERIA PENAL. Diario Oficial de la Federación. Recuperado el 22 de Mayo de 2020, de http://www.diputados.gob.mx/LeydeesBiblio/pdf/LNMASCMP_291214.pdf, 2014. 
Revista Eletrônica de Direito Processual - REDP

Rio de Janeiro. Ano 15. Volume 22. Número 1. Janeiro a Abril de 2021

Periódico Quadrimestral da Pós-Graduação Stricto Sensu em Direito Processual da UERJ

Patrono: José Carlos Barbosa Moreira (in mem.). ISSN 1982-7636. pp. 752-780

www.redp.uerj.br

\subsection{La Ley Nacional de Ejecución Penal y las bondades de los procesos restaurativos}

En materia de ejecución penal, y en el sistema de justicia integral para adolescentes, son las dos áreas donde más se ha trabajado en materia de JR en la nación Azteca, reflejándose estos aspectos en las leyes orgánicas promulgadas.

La Ley Nacional de Ejecución Penal— en lo adelante LNEP—, promulgada en fecha 6 de junio del 2016, incorpora algunos procesos restaurativos, lo que constituye una nota relevante, puesto que en las normas de las entidades federativas no se contemplaba de esta manera. El cuerpo legal incorpora una denominación más abarcadora de la reparación del daño, "reparación integral", considerando las imprecisiones previstas en otras normativas, lo que permite establecer una dimensión real sobre el resarcimiento del daño, y satisfacer las necesidades de la víctima que difícilmente se cumplen con la aplicación del modelo de justicia tradicional ${ }^{538}$.

Un aspecto relevante de esta ley es que se ilustra sobre el objeto de aplicación de la JR, en la fase de ejecución penal, enunciándose todos los atributos indispensables de esta institución ${ }^{539}$.

Sin embargo, de la lectura del artículo, y los siguientes de este título, se advierte que no hay una descripción de los procesos restaurativos que podrán utilizarse en favor del arreglo de la víctima y el ofensor, con la participación de la comunidad. Solo puede colegirse, de la propia configuración legal del art.200, que el modelo empleado es la Junta Restaurativa porque la conceptualización es casi una réplica de la incorporada a la LNMASCMP ${ }^{540}$.

\footnotetext{
${ }^{538}$ MALtos RodríGUEZ, María. "La justicia restaurativa en las Leyes nacionales mexicanas”. Recuperado el 12 de Mayo de 2020, de http://biblioteca.cejamericas.org: http://biblioteca.cejamericas.org/bitstream/handle/2015/5530/MariaMaltos_Lajusticiarestaurativa_REV20.pdf?se quence $=1 \&$ is Allowed $=\mathrm{y}, 2017$.

${ }^{539}$ Ley Nacional de Ejecución Penal. Diario Oficial de la Federación. Recuperado el 24 de Mayo de 2020, de www.diputados.gob.mx: http://www.diputados.gob.mx/Ley deesBiblio/pdf/LNEP_090518.pdf:, 2016.

artículo 200. Objeto de la Justicia Restaurativa en la ejecución de sanciones. En la ejecución de sanciones penales podrán llevarse procesos de Justicia Restaurativa, en los que la víctima u ofendido, el sentenciado y en su caso, la comunidad afectada, en libre ejercicio de su autonomía, participan de forma individual o conjuntamente de forma activa en la resolución de cuestiones derivadas del delito, con el objeto de identificar las necesidades y responsabilidades individuales y colectivas, así como a coadyuvar en la reintegración de la víctima u ofendido y del sentenciado a la comunidad y la recomposición del tejido social.

${ }^{540}$ Maltos RodríGUEZ, María. "La justicia restaurativa en las Leyes nacionales mexicanas”, Op. Cit., p. 40.
} 
Por otro lado, la disposición regulatoria de ejecución de penas, no solo se limita a señalar el modelo restaurativo heredado de la LNMASCMP; sino que en su configuración presenta dos aspectos renovadores. En primer orden, la ley, además de la Junta Restaurativa, privilegia otras metodologías de intervención a las que podemos llamar prácticas restaurativas debido a la versatilidad y amplitud de su instrumentalización. Estas prácticas están identificadas como programas y encuentros, el primero enfocado a la figura del infractor, y la búsqueda de la revalorización de su conducta, a partir del resultado provocado en la persona perjudicada. La otra denominación, es la de encuentros o sesiones conjuntas víctima-ofensor, y donde el facilitador tendrá un papel relevante en el progreso de la comunicación entre las partes, así como canalizar las propuestas planteadas por los intervinientes, a fin de lograr un acuerdo que todos estén dispuestos a aceptar como resultado de la sesión, según lo dispuesto en el art. 204 de esta normativa $^{541}$.

El segundo aspecto renovador viene implícito en lo referido anteriormente, y es, que estas metodologías restaurativas no van enfocadas exclusivamente a la participación colectiva-a través de la intervención colaborativa de la víctima, ofensor y comunidad-; sino que también pueden implementarse con una orientación individual, permitiendo, en ausencia de las víctimas, a la persona privada de libertad, reflexionar sobre el daño causado y conducirse en lo adelante con un comportamiento adecuado.

Por otra parte, el cuerpo legal mencionado habilita la utilización de los procesos y prácticas restaurativas para todos los tipos penales obrantes en la legislación sustantiva-art. 202-, lo que permite que puedan invocarse en delitos de mayor entidad. Dichos modelos con enfoque reparador podrán ser implementados a partir de la emisión de la sentencia condenatoria y en caso de que, por acuerdo de las partes, se opte por el mismo, el órgano jurisdiccional canalizará la solicitud al área correspondiente.

\footnotetext{
${ }^{541}$ Ley Nacional de Ejecución Penal...op. cit., pp.70-71.

artículo 204. Procesos restaurativos Los procesos restaurativos se llevarán a cabo con la participación del sentenciado en programas individuales o sesiones conjuntas con la víctima u ofendido, en las cuales podrán participar miembros de la comunidad y autoridades, atendiendo al caso concreto y con el objetivo de analizar con las consecuencias derivadas de delito. Los procesos de justicia restaurativa en los que participe la víctima.
} 
De lo referido en este acápite, se desprende que no existen límites para suscribir acuerdos en cuanto a la materia disponible, y ello pudiera representar una incongruencia con lo reflejado en el CNPP, considerando las restricciones para acoger las salidas alternas. Sin embargo, desde la óptica de la etapa del proceso en que se implementa esta normativa, hay que considerar que los acuerdos alcanzados no se perfilan como una solución alterna que persigue la extinción de la acción penal, sino que su efecto está dirigido exclusivamente a la reparación del daño, y la responsabilización del hecho por el ofensor. Por lo que, en ese sentido, no encuentran ninguna limitación ni en materia catálogo de delitos, ni en la condición legal con la que responden penalmente los ofensores, o sea, el carácter de primario, o reincidentes.

Como último aspecto hay que mencionar que, si el sentenciado decide acogerse a los procesos restaurativos, el Juez de Ejecución lo considerará como parte del plan de actividades, que se contemplan en el régimen penitenciario, dentro de la organización de los tiempos y espacios en que cada persona privada de la libertad realizará sus actividades laborales, educativas, culturales, de protección a la salud, y deportivas ${ }^{542}$.

\subsection{El enfoque restaurativo de la Ley Nacional del Sistema Integral de Justicia Penal para Adolescentes (LNSIJA), y su Efecto dinamizador en el ordenamiento penal mexicano}

La legislación procesal en materia juvenil constituye dentro del ordenamiento jurídico mexicano el referente más importante en materia de justicia alternativa, considerando que en su entramado normativo se condensan todas las metodologías de intervención de la justicia alternativa, y también las salidas alternas al proceso penal.

En cuanto el enfoque restaurativo, cabe señalar que esta normativa, es la que impulsa en mayor medida, los postulados de la JR, a partir de su reconocimiento como principio desde la misma norma procesal ${ }^{543}$.

\footnotetext{
${ }^{542}$ Ibidem, p. 70.

${ }^{543}$ Ley Nacional del Sistema Integral de Justicia Penal para Adolescentes. Diario Oficial de la Federación. Recuperado el 24 de Mayo de 2020, de http://www.diputados.gob.mx/LeydeesBiblio/pdf/LNSIJPA, 2016, p.5. artículo 21: Justicia Restaurativa El principio de Justicia restaurativa es una respuesta a la conducta que la Ley de señala como delito, que respeta la dignidad de cada persona, que construye comprensión y promueve armonía social a través de la restauración de la víctima u ofendido, la persona adolescente y la comunidad. Este principio puede
} 
El reconocimiento de la JR como principio, trae consigo la obligatoria virtualización de sus postulados, en consonancia con lo reflejado en la Constitución en materia de MSC, y que propicia que desde la propia ley procesal juvenil se reconozca una vía no adversarial accesible para los ciudadanos. Por otro lado, todas las decisiones que adopten las autoridades deberán prestar atención a lo refrendado en este principio.

Otro aspecto interesante sobre el reconocimiento y virtualidad de la JR como regla fundamental, es que propicia la aplicación de modelos restaurativos con intervención colectiva, considerando a los protagonistas del conflicto y la comunidad; y también establece la posibilidad del trabajo individual en la búsqueda de la satisfacción y reparación ${ }^{544}$.

Ahora bien, hay un aspecto que pudiera considerarse el más relevante, y tiene que ver con la conveniencia de establecer un vínculo legal estrecho entre los MSC y las salidas alternas al proceso-Art.82 y Art.93 de la LNSIJA -, lo que genera un grado de conexidad importante en las estructuras del modelo de justicia alternativa, propiciándose una instrumentación adecuada y soluciones más efectivas. Esto, por lo menos en el ámbito juvenil, suple las falencias del CNPP, en cuanto a la ausencia de una disposición concreta sobre los mecanismos alternos y los modelos restaurativos en el ámbito procesal de adultos, debiendo remitirse a la LNMASCMP, aspecto que genera una incongruencia jurídica, puesto que los principales postulados y figuras procesales-así como principios y conceptualizaciones de corte adjetivo- deben refrendarse bajo la norma procesal, aunque después resulte necesario remitir a una legislación especial.

En este sentido, la LNSIJA logra suplir las ausencias detectadas en el CNPP, sin ello se contraponga a los dispuesto en LNMASCMP, ya que la ley de mecanismos tiene un efecto tonificador, sobre el marco jurídico de las modalidades pacíficas de gestión de conflictos, y esto propicia que pueda esclarecer, complementar y servir de marco de referencia, ante cualquier duda que pueda surgir con motivo de la operatividad de estos procesos.

Como elemento contrastante, la ley procesal juvenil, mantiene la misma línea que el CNPP, sobre incluir en una misma denominación los MSC y las metodologías restaurativas. Sin

desarrollarse de manera individual para las personas mencionadas y sus respectivos entornos y, en la medida de lo posible, entre ellos mismos, a fin de reparar el daño, comprender el origen del conflicto, sus causas y consecuencias.

${ }^{544}$ Maltos RodríGuez, María. "La justicia restaurativa en las Leyes nacionales mexicanas”. Op. cit. p. 42. 
embargo, se introduce un componente novedoso, la denominación de "procesos restaurativos", integrándose en esta modalidad: la reunión de la víctima con la persona adolescente, la Junta Restaurativa y los círculos. La inclusión de estos nuevos modelos de justicia reparadora permite diversificar los esquemas de intervención restaurativa, y la participación de la comunidad afectada; también a los operadores del sistema de justicia para adolescentes, como nuevos actores, a fin coadyuvar a que los protagonistas puedan enfrentar los hechos de una manera pacífica.

Hay que agregar que, en cuanto a la pertinencia del acuerdo reparatorio, la ley solo restringe la suscripción a los delitos de violencia familiar-Art. 96 de la LNSIJA一, por lo que se contempla un catálogo más amplio de delitos mediables, y en consecuencia mayores posibilidades extinguir la acción penal, mediante una salida alterna al proceso. Esta circunstancia, cambia en la fase de ejecución penal donde se prevé la posibilidad de aplicar los procesos restaurativos para todos los delitos, período en que el acuerdo no representaría una salida anticipada al proceso, sino que se enfocaría en la reparación del daño.

Otro aspecto significativo, es la posibilidad de que lo convenido a través de los MSC o las metodologías restaurativas, pueda materializarse a través de un acuerdo reparatorio, o también desde el plan de reparación que opera como condición, en la suspensión condicional del proceso. Lo referido, supone entonces la posibilidad de encontrar una solución alterna hasta en delitos de violencia familiar-vetados para celebrar acuerdos reparatorios-, tomando en cuenta que nada impide que pueda desahogarse el mecanismo por vía de la suspensión condicional del proceso $^{545}$ :

Lo anterior demuestra, que la LNSIJA ha venido a suplir todas las vicisitudes de los MSC, en la ley procesal de adultos, logrando no solo diversificar las formas de solución pacífica de conflictos, sino que ofrece algunas alternativas para que estos puedan materializarse, en función privilegiar el derecho de los ciudadanos- en este caso de los menores- de acceder a una

\footnotetext{
${ }^{545}$ Ley Nacional del Sistema Integral de Justicia Penal para Adolescentes. Op. cit., p.25.

artículo 93. Del acuerdo: Los acuerdos alcanzados a través de los mecanismos establecidos en este Título, se tramitarán conforme a lo establecido en el Título siguiente, ya sea como acuerdos reparatorios o como propuesta del plan de reparación y sugerencias de condiciones por cumplir para la suspensión condicional del proceso.
} 
justicia más participativa, en todas las etapas del proceso penal, y con especial atención a la fase de ejecución penal.

\subsection{La Justicia Restaurativa en la ejecución de las medidas de sanción en la LNSIJA}

La fase de ejecución del código procesal juvenil establece parámetros similares a la ley federal de adultos-LNEP-, con relación a los efectos derivados de los acuerdos en la etapa de cumplimiento de pena, en donde el fin perseguido, será la reparación del daño, y no la extinción de la acción penal, puesto que ya hay una sentencia firme. Por tanto, será viable este modelo a todos los delitos, y no contradice en modo alguno, los aspectos reflejados en fases predecesoras, ni tampoco colisiona esto, con otras formas de gestión pacífica de conflictos. Lo que sí, es válido señalar, es que la consecución del acuerdo no conllevará ningún beneficio de excarcelación anticipada.

\section{Análisis sobre tratamiento jurídico del enfoque restaurativo en la legislación nacional de Panamá}

Por su parte Panamá, también es uno de los países que va a la vanguardia con respecto a la instrumentalización de MSC. Aunque si bien es cierto los MSC, no están regulados en la Carta Magna - solo se enuncia en el artículo 202 lo concerniente a la justicia arbitral一, sus mayores aciertos están en las leyes orgánicas, con la introducción de fórmulas no adversariales con relevancia especial en el ámbito penal en virtud de la promulgación de la Ley No.63, del 28 de agosto del 2008, Código Procesal de la República de Panamá, legislación que incluiría la mediación y la conciliación como figuras no adversariales, con un procedimiento exclusivo ${ }^{546}$.

La actualización del sistema de justicia ha calado también en las instituciones gubernamentales que abogan por una justicia más participativa, y una actuación expedita, trasparente y efectiva de los órganos jurisdiccionales. A esto se ha sumado, la especialización

\footnotetext{
546 SÁNCHEZ García, Arnulfo; FernÁNDEZ SILVA, Yulisán. El interés superior del menor en el marco de la utilización de los métodos alternos de solución de conflictos en el ámbito penal, Op. cit., pp. 121-139.
} 
de operadores de los MSC, a través de programas de capacitación y postgrados, impulsados por el Órgano Judicial; resalta entre los programas de superación el Doctorado en Métodos Alternos de Solución de Conflictos en colaboración con la Universidad Autónoma de Nuevo León, para formar a jueces, magistrados y funcionarios judiciales en general ${ }^{547}$.

Sin embargo, la actualización del modelo de justicia penal de Panamá no estuvo perfilado a la consolidación de procesos restaurativos, sino más bien a fórmulas autocompositivas como la mediación y la conciliación, lo que significa que se visualizan áreas de oportunidad, proclives a la introducción del paradigma restaurativo y sus metodologías de intervención, lo que permitirá una verdadera consolidación del derecho de accedo a la justicia y también la construcción de un nuevo modelo de justicia penal.

\subsection{Los Programas de Resocialización con contenido restaurativo, en la fase de ejecución Penal de la Ley No.63 del 2008, que adopta el Código Procesal Penal}

La legislación procesal penal de Panamá, a diferencia del ordenamiento penal mexicano, no cuenta con una normativa especial en material de ejecución penal, de ahí que, los preceptos que regulan el procedimiento pos-condena se encuentran consignado en la Ley No.63 del 2008, que adopta el Código Procesal Penal.

En ese sentido, con la puesta en vigor de la legislación procesal y su correspondencia con el Código Penal del 2007, se inserta una nueva figura jurisdiccional, que se le denomina Juez de cumplimiento, autoridad encargada del seguimiento al procesado, considerando su status procesal ya sea privado de la libertad, o beneficiado con la suspensión condicional de la ejecución de la sanción, o, que le sea concedido el beneficio la libertad condicional, pues en cualquiera de estas circunstancias, continúa sometido a la vigilancia de la pena, por no haberse extinguido totalmente. Otras funciones del Juez de cumplimiento están vinculadas a la resolución de todas las solicitudes presentadas por el fiscal y el defensor. Estas peticiones están relacionadas con la actualización, modificación o suspensión de la condición procesal del sancionado, lo que significa ser garante del aspecto resocializador- ello contempla la

547 Ídem 
Revista Eletrônica de Direito Processual - REDP

Rio de Janeiro. Ano 15. Volume 22. Número 1. Janeiro a Abril de 2021

Periódico Quadrimestral da Pós-Graduação Stricto Sensu em Direito Processual da UERJ

Patrono: José Carlos Barbosa Moreira (in mem.). ISSN 1982-7636. pp. 752-780

www.redp.uerj.br

posibilidad de desprisionalización a condenados que mantengan buena conducta y posibilidad de reinserción social — de la pena y verificador de las condiciones del sentenciado ${ }^{548}$.

Ahora bien, en materia de JR, la legislación procesal no ha incorporó dispositivos alternos de solución de controversias. En contraposición a ello, se introdujeron figuras que pudieran caracterizarse con ciertos tintes restaurativos ${ }^{549}$, como pueden ser: las medidas alternas al cumplimiento de la pena de privación de la libertad, art. 57 del Código Penal; y, la suspensión condicional de la ejecución de la pena, figura recogida en el art. 98 de la norma sustantiva y el art.509 apartado IV de legislación adjetiva.

En el caso de las medidas alternas del cumplimiento de la pena, estas tienen un enfoque resocializador puesto que le conceden al sancionado la oportunidad de incorporarse a un programa de trabajo o estudio, que, de acuerdo con su comportamiento, podrá desplegarse dentro o fuera del centro penitenciario. Entre las medidas que se contemplan en el art. 57 se encuentran: La educación con provecho académico, en los distintos niveles de enseñanza; El trabajo en labor comunitaria no remunerado; y, la participación como instructor en cursos de alfabetización, de educación, de adiestramiento o de capacitación, la que se computará por cada ocho horas laboradas como un día de trabajo ${ }^{550}$. Lo anterior, se concatena con la potestad concedida al Juez de cumplimiento, de sustituir hasta el 30\% de las penas de prisión impuesta, por otras penas menos estigmatizantes como el trabajo comunitario, arresto domiciliario, días multas o una compensación económica a la víctima, ya sea de forma individual o mixta ${ }^{551}$.

Por otro lado la suspensión condicional de la ejecución de las penas, permite por medio de la figura del Juez de cumplimiento, que las sanciones impuestas al infractor, - ya sea la pena de prisión, el arresto de fines de semana, la reclusión domiciliaria o inclusive la de días-multa一, puedan suspenderse por un término de dos a cinco años, siempre y cuando el sancionado se

\footnotetext{
${ }^{548}$ Rangel Buitrago, Sherly Chantal. Ejecución Penal y Medidas de Seguridad. En M. PÚBLICO, CóDIGO PROCESAL PENAL DE LA REPÚBLICA DE PANAMÁ (COMENTADO), Ciudad de Panamá: Procuraduría General de la Nación, 2018, p. 266.

${ }^{549}$ ESPAÑA LOZANO, Jesús. "Análisis de la justicia restaurativa y la conciliación penal a la luz de la suspensión condicional del proceso". En GORJÓN GÓMEZ, Gabriel de Jesús. Tratado de Justicia Restaurativa, Un enfoque integrador, Ciudad de México: tirant lo blanch, 2017, p.252

${ }^{550}$ De CASTRO, Delia. TEXTO ÚNICO DEL CÓDIGO PENAL DE LA REPÚBLICA DE PANAMÁ. (Comentado): PROCURADURÍA GENERAL DE LA NACIÓN, 2015, p.50.

551 Ídem
} 
sometiere a un grupo de condiciones dispuestas en ley: que sea infractor primario de la norma, y además haber cumplido con los términos de la reparación de la víctima, o al menos, haberse comprometido a cumplir satisfactoriamente el resarcimiento al afectado ${ }^{552}$. No obstante, la institución mencionada cuenta con una limitante de aplicación-un aspecto que se diferencia notablemente con la legislación mexicana-, y es que solo pueden ser elegibles para este beneficio, los sancionados a penas de hasta 3 años de privación de libertad; eliminándose esta condición, para las sanciones de arresto de fines de semana, de prisión domiciliaria, o de díasmulta.

Es decir, la ausencia de metodologías restaurativas en la fase de ejecución penal de la legislación procesal panameña es visible, pero esto no obsta para que dentro del ordenamiento procesal puedan visualizarse algunos preceptos con proyección a la justicia reparadora. En el caso de las medidas alternas a la pena, estas tienen por propósito reconducir la conducta del infractor y convidarle a reinsertarse en la sociedad con un comportamiento responsable. Lo referido, propicia la responsabilización del sancionado por los actos reprochables, y actuar en consecuencia, para generar un compromiso de no repetición; aspectos que convergen con los postulados de la JR. Por otra parte, la suspensión condicional de la ejecución de las penas propicia la reparación del daño en su afectación real, considerando el criterio de la víctima, generando un clima de acercamiento y comunicación, que favorece el saneamiento de las heridas emocionales. Estos factores constituyen esbozos del enfoque restaurativo, y develan un área de oportunidad propensa al asentamiento definitivo de la JR en la legislación procesal nacional.

\subsection{La Ley no. 40 de 1999, Régimen Especial de Responsabilidad Penal para la Adolescencia (RERPA)}

Derivado de los cambios progresivos y la constante evolución del marco legal de Panamá en materia de adolescentes y menores, surge la necesidad de regular para que los adolescentes puedan crecer y desarrollarse dentro de una sociedad donde el Estado les reconozca y salvaguarde sus derechos, sin importar su etnia, género, ni condición social, garantizándoles su

552 Ídem 
Revista Eletrônica de Direito Processual - REDP

Rio de Janeiro. Ano 15. Volume 22. Número 1. Janeiro a Abril de 2021

Periódico Quadrimestral da Pós-Graduação Stricto Sensu em Direito Processual da UERJ

Patrono: José Carlos Barbosa Moreira (in mem.). ISSN 1982-7636. pp. 752-780

www.redp.uerj.br

presente y su futuro. De tal forma, que el en año de 1999; se instaura la Ley No. 40 la cual establece el Régimen Especial de Responsabilidad Penal para La Adolescencia- en adelante (RERPA)- con la intención de sistematizar la administración de justicia juvenil, que tiene como propósito elemental la "protección integral de la infancia".

El concepto de protección integral de la infancia se propagó en la década de los noventa por toda América Latina, el cual se basa en los postulados de intervención mínima, flexibilización de la respuesta penal y aplicación mínima de las prerrogativas previstas en la jurisdicción ordinaria, siendo estos los principios claves en la implementación de modelos de Justicia Restaurativa ${ }^{553}$, en los que el Estado debe de velar por el interés superior de la niñez y la adolescencia ${ }^{554}$ de la Ley 40 de 1999 del Régimen Especial de Responsabilidad Penal para la Adolescencia. De este modo, se pretendía armonizar el marco normativo del país específico, integrando a su legislación lo concerniente en materia de adolescentes, menores o de familia, las convenciones, estatutos y tratados sobre los derechos del niño o niña, menores o adolescentes que fuera parte ${ }^{555}$.

Partiendo de esta doctrina, se muestra el análisis de la Ley No. 40 de 1999, del Régimen Especial de Responsabilidad penal para la adolescencia para conocer la relación existente con la JR aplicada a adolescentes en el ámbito penal, de ahí que el artículo $1^{556}$, se establezcan los términos y condiciones en que los adolescentes y las adolescentes son responsables por las infracciones que cometan contra la ley penal, además, se faculta a determinados órganos judiciales para la creación de instituciones y procedimientos específicos en la jurisdicción de menores y reglamenta el régimen especial de custodia, protección y educación de menores privados de libertad.

$\mathrm{Al}$ respecto, con base en las particularidades que identifican a los diversos procesos que admite la Justicia Restaurativa, dentro del artículo 4, párrafo primero y cuarto- se expresan las

\footnotetext{
${ }^{553}$ Ministerio de Gobierno de la República de Panamá, \& Fondo de las Naciones Unidas para la Infancia. Marco legal de justicia penal adolescente. Panamá: UNCEF/ MGRP, 2017, p. 7.

${ }^{554}$ Ley 40 de 1999 del Régimen Especial de Responsabilidad Penal para la Adolescencia, de Procuraduría General de la Nación. Recuperado el 28 de Mayo de 2020, de https://www.unicef.org/panama/media/761/file.

${ }^{555}$ O’DonNell, Daniel. Anuario del XIX Congreso Panamericano del Niño. La Doctrina de la Protección integral y las normas jurídicas vigentes en relación a la familia, Monterrey, 2004, p. 142.

${ }^{556}$ Ley 40 de 1999 del Régimen Especial de Responsabilidad Penal para la Adolescencia, Op. cit., p. 10.
} 
finalidades primordiales ${ }^{557}$, como la resocialización de los infractores, es decir, que la única finalidad de la sanción es que se asegure su reinserción en la familia y en la sociedad, a través del aprendizaje de una actitud constructiva en relación con su entorno. Lo referido, se patentiza en los postulados de la Justicia Restaurativa, los cuales explican que, dentro de la reparación del daño causado, se deben generar condiciones óptimas para el infractor hacia su posible reintegración social, así como organizar el sistema de instituciones que intervienen en la investigación del acto infractor, en el juzgamiento de adolescentes y en la resolución no litigiosa de conflictos, artículo 6- párrafo primero-.

Así mismo, esta ley se refiere a la existencia del principio de finalidad y proporcionalidad de la sanción y sobre la finalización de estas, aludiendo que las sanciones que se les impongan sean conducentes y tengan como fin la resocialización del adolescente, siendo obligación del Juez de cumplimiento velar por esa observancia, del mismo modo se concede a los adolescentes la posibilidad, pero a la vez, la obligatoriedad de participar en programas de asistencia y orientación de carácter socioeducativas como la amonestación, la participación obligatoria en programas de asistencia, la prestación de servicios a la comunidad y la reparación de daños a la víctima, artículos $16.14,125$ y 130-134 de la RERPA ${ }^{558}$, pretendiendo proporcionar un enfoque restaurativo en beneficio del adolescente, y lo encuentre como un área de oportunidad para la reconstrucción del tejido social.

La relación con los elementos personales que integran la noción de proceso restaurativo que expone e $\mathrm{e}^{559} \mathrm{y}$ el informe del ${ }^{560}$ sobre los sujetos indirectos que participan en los procesos restaurativos, se contempla de forma similar en esta Ley en los artículos 48, 127, 128 de la Ley 40 de 1999 del Régimen Especial de Responsabilidad Penal para la Adolescencia ${ }^{561}$, el

\footnotetext{
${ }^{557}$ Ibidem, p. 11.

${ }^{558}$ Ibidem, pp. 14,58 y 59-61.

559 Oficina de las Naciones Unidad contra la Droga y el Delito. Manual sobre Programas de Justicia Restaurativa. Serie de Manuales sobre Justicia Penal. Obtenido de https://www.unodc.org/documents/justice-and-prisonreform/Manual_sobre_programas_de_justicia_restaurativa.pdf, 2006, p. 6.

560 Organización de las Naciones Unidas \& Comisión de Prevención del Delito. Debate temático sobre la reforma del sistema de justicia penal: logro de la eficacia y la equidad. Reglas y normas de las Naciones Unidas en materia de prevención del delito y justicia penal. Obtenido de https://www.unodc.org/documents/commissions/CCPCJ/CCPCJ_Sessions/CCPCJ_11/E-CN15-2002-05-Add1/ECN15-2002-5-Add1_S.pdf, 2002, p. 10.

${ }^{561}$ Ley 40 de 1999 del Régimen Especial de Responsabilidad Penal para la Adolescencia, Op. cit., pp. 32 y 59.
} 
involucramiento y participación de manera activa de familiares, tutores o responsables del adolescente en diversas parte del proceso penal; esto es, durante el proceso: en el estudio psicosocial del adolescente o como testigos del hecho investigado y en la culminación del proceso: en la ejecución de medidas cautelares o en el cumplimiento las sanciones impuestas. Al mismo tiempo, manifiesta que la forma de aplicación de las sanciones deberá tener objetivos primordialmente educativos, preferentemente con la intervención de la familia, la comunidad, y con la asistencia de especialistas. Esto permite la visibilización de la Justicia Restaurativa a través de la inclusión de familiares o allegados, profesionales de la judicatura, trabajadoras sociales, abogados o representantes de la comunidad, fomentando el diálogo y la cooperación para poder tener sociedades más pacíficas, libres de violencia y conflicto.

La propia ley compete a los Jueces penales para conocer en primera instancia sobre la suspensión condicional del proceso, para los casos en que el adolescente reúna dos requisitos: que el delito cometido admita la conciliación; y que el adolescente haya realizado esfuerzos por reparar el daño causado, o que el acto cometido no puso en grave peligro ni la integridad física de las personas ni sus bienes. También concede el beneficio a las formas de terminación anticipada del proceso a los adolescentes, como la remisión, el criterio de oportunidad, la conciliación, cuando los delitos cometidos por estos causan daños leves o insignificante o cuando el adolescente tenga escasa participación en el delito -artículos 21.8, 98, 17.7, 66-78 y 131 de la RERPA ${ }^{562}$, incidiendo en ambigüedad respecto de lo que comprenden los MSC y las salidas alternas del proceso penal, ya que no explica la diferencia de lo que representan ambos esquemas de justicia.

Siendo esta la forma en que la Justicia Restaurativa manifiesta sus postulados, y bondades aplicadas en materia penal para adolescentes, entrando paulatinamente en un área del derecho muy sensible por tratarse con menores y adolescentes. Además, impulsa al Estado panameño en la creación de instituciones e inclusión de la comunidad para llevar a cabo el papel importantísimo de salvaguardar los derechos de las y los adolescentes, manifestando compromiso en el acompañamiento cuando un adolescente ha cometido un delito y generándole

562 Ibidem, pp. 18, 20-21, 39-42 у 60. 
condiciones para que el adolescente consiga reparar el daño causado y logrando así su posible reincorporación a la sociedad.

Pero también se hace necesaria la incorporación de los diversos procesos de Justicia Restaurativa a esta legislación para facilitar el derecho de acceso a la justicia y para no estar combinando e improvisando que debería aplicarse en pro del adolescente, produciendo simplicidad y economía procesal dentro de los juicios y procesos penales.

\section{Conclusiones}

Como ideas finales puede plantearse que, en las legislaciones penales juveniles de México y Panamá, existe una mayor flexibilización mediante la introducción de preceptos y figuras que permiten alejarse del modelo de justicia tradicional e implementar nuevos esquemas de corte colaborativo, buscando estrategias más inclusivas, y a la vez menos lesivas para los adolescentes, en consonancia con la protección al Interés Superior de la niñez y la adolescencia. En ese sentido, la Ley Nacional del Sistema Integral de Justicia Penal para Adolescentes ha incorporado los principios esenciales de la JR, desarrollando un catálogo de procesos restaurativos, que posibilita diversificar las fórmulas pacificas de solución de conflictos, considerando además que la propia ley dispone las salidas alternas que materializarán la aplicación del enfoque reparador, aspecto que sin dudas conecta con la sinergia que debe existir entre los preceptos de una normativa.

En Panamá, por su parte, en enfoque se ha dirigido a establecer algunos preceptos que pueden conducir a prácticas restaurativas como la resocialización de los infractores y la reparación del daño causado, por medio del aprendizaje de una actitud constructiva hacia su entorno, que determina la reintegración social del individuo, postulados que se refrendan en la Justicia Restaurativa. Este perfil de las leyes penales juveniles tiene la misma configuración legal, en las normativas que remiten a la fase de ejecución penal de ambos países.

Por otro lado, aunque México cuenta con una La Ley Nacional de Mecanismos Alternativos de Solución de Controversias en Materia penal, a diferencia de Panamá, que introdujo la modalidades no adversariales en la legislación procesal; la normativa de la nación 
Azteca no cuenta con una denominación específica de procesos restaurativos, y la metodología restaurativa que se reconoce, es la Junta Restaurativa, contemplada como un mecanismo alterno, de similar construcción a la mediación y la conciliación, lo que impide una cabal compresión sobre la distinción entre las metodologías restaurativas, y dispositivos alternos de solución de conflicto.

En consecuencia, los fundamentos teóricos, principios y definiciones sobre los modelos restaurativos, deberán estar contemplados en las leyes procesales nacionales, y de esa manera replicarse en las leyes adjetivas para adolescentes, considerando que el enfoque restaurativo, constituye un rubro dinamizador de los modelos de enjuiciamiento, por ello adquiere un carácter relevante en todo el sistema de justicia penal.

\section{REFERENCIAS}

ACHUTTI, Daniel. "Abolicionismo penal y justicia restaurativa: del idealismo al realismo político-criminal”. Revista de Derechos Humanos y Estudios Sociales, Año VII(13), 55$74,2015$.

Albertí i Cortés, M. \& Pedrol Llirinós, M. "El enfoque restaurativo en el ámbito educativo. Cuando innovar en la escuela. Educación Social”. Revista d'Intervenció Socioeducativa, 47-72, 2017.

BRITTO RUIZ, Diana. JUSTICIA RESTAURATIVA: Reflexiones sobre la Experiencia de Colombia. Loja: Universidad Técnica Particular de la Loja. 2010.

Carlín Balboa, A. MANUAL BÁSICO DE JUSTICIA PARA ADOLESCENTES, México D.F, México: Poder Judicial del Estado de Nuevo León, 2018.

ChOYA Forés, Nastia. Prácticas restaurativas: círculos y conferencias. Recuperado el 23 de Mayo de 2020, de Sociedadvascavictimologia. org,: Http: //Sociedadvascavictimologia. org, 2015, p. 9. En CARNeVAli RodRíGUEZ, Raúl. "La justicia restaurativa como mecanismo de solución de conflictos. Su examen desde el derecho penal”. Justicia juris, 13(1), 122-132, 2017. 
Código Nacional de Procedimientos Penales. Diario Oficial de la Federación. Recuperado el 26 mayo de 2020, de http://www.diputados.gob.mx/LeyesBiblio/pdf/CNPP_220120.pdf , 2014.

De CASTRo, Delia. TEXTO ÚNICO DEL CÓDIGO PENAL DE LA REPÚBLICA DE PANAMÁ. (Comentado): PROCURADURÍA GENERAL DE LA NACIÓN, 2015.

DíAz MADRIGAL, I. N. La mediación en el sistema de justicia penal: justicia restaurativa en México y España. Serie Juicios Orales. núm. 9. México, D.F, 2016.

DOMINGO DE LA FUENTE, Virginia. "Justicia restaurativa como ciencia penal o social, encaminada a mejorar la justicia. Educación Social”. Revista d'Intervenció Socioeducativa (67), 73-90, 2017.

ESPAÑA LOZANO, Jesús. "Análisis de la justicia restaurativa y la conciliación penal a la luz de la suspensión condicional del proceso". En GORJÓN GÓMEZ, Gabriel de Jesús. Tratado de Justicia Restaurativa, Un enfoque integrador, (págs. 237-252), Ciudad de México: tirant lo blanch, 2017.

Fernández Pereira, Julio A. Temas para el estudio del Derecho Procesal Penal. Parte I. La Habana: Editorial Félix Varela, 2002.

FERRAJOLI, Luigi. "El derecho penal mínimo". Poder y control, vol. 10, 1-25, 1986.

GoJón GÓMEZ, Gabriel de Jesús \& VILLEDA, Brenda Judith. "Justicia restaurativa, una herramienta de paz en la resolución de conflictos comunitarios". Caso Nuevo León. Política criminal, 13(25), 548-571, 2018.

Graillet GonzÁlez, Eleazar. DE LA JUNTA RESTAURATIVA. En VÁSQUEZ GÁNDARA, Carlos Antonio. LEY DE NACIONAL DE MECANISMOS ALTERNATIVOS DE SOLUCIÓN DE CONTROVERSIAS EN MATERIA PENAL COMENTADA (pág. 143), Veracruz: Universidad de Xalapa, 2015.

Ley 40 de 1999 del Régimen Especial de Responsabilidad Penal para la Adolescencia, de Procuraduría General de la Nación. Recuperado el 28 de Mayo de 2020, de https://www.unicef.org/panama/media/761/file, 1999.

LEY DE DE MECANISMOS ALTERNATIVOS PARA LA SOLUCIÓN DE CONTROVERSIAS PARA EL ESTADO DE NUEVO LÉON. PERIÓDICO OFICIAL 
Revista Eletrônica de Direito Processual - REDP

Rio de Janeiro. Ano 15. Volume 22. Número 1. Janeiro a Abril de 2021

Periódico Quadrimestral da Pós-Graduação Stricto Sensu em Direito Processual da UERJ

Patrono: José Carlos Barbosa Moreira (in mem.). ISSN 1982-7636. pp. 752-780

www.redp.uerj.br

DEL ESTADO. Recuperado el 23 de Mayo de 2020, de http://www.hcnl.gob.mx/trabajo_legislativo/Ley dees/Ley dees/Leyde_de_mecanismos_alternativos_para_la_solucion_de_controversias_para_el_ Estado_de_nuevo_leon/, 2017.

LEY DE NACIONAL DE MECANISMOS ALTERNATIVOS DE SOLUCIÓN DE CONTROVERSIAS EN MATERIA PENAL. Diario Oficial de la Federación. Recuperado el 22 de Mayo de 2020, de /www.diputados.gob.mx: http://www.diputados.gob.mx/Ley deesBiblio/pdf/LNMASCMP_291214.pdf, 2014.

Ley Nacional de Ejecución Penal. Diario Oficial de la Federación. Recuperado el 24 de Mayo de 2020, de www.diputados.gob.mx: http://www.diputados.gob.mx/Ley deesBiblio/pdf/LNEP_090518.pdf, 2016.

Ley Nacional del Sistema Integral de Justicia Penal para Adolescentes. Diario Oficial de la Federación. Recuperado el 24 de Mayo de 2020, de http://www.diputados.gob.mx/LeydeesBiblio/pdf/LNSIJPA, 2016.

LlOBEt RodRígueZ, J. Justicia Restaurativa y la Protección de la Víctima. Libro en Homenaje a Julio Maier, pp. 873-886, 2005.

MaIER, Julio. Derecho Procesal Penal.Tomo II. Parte general.Sujetos procesales (1ra ed.). Buenos Aires: Editores del Puerto s.r.l, 2003.

MAltos RodríGUEZ, María. "La justicia restaurativa en las Leyes nacionales mexicanas". Recuperado el 12 de Mayo de 2020, de http://biblioteca.cejamericas.org: http://biblioteca.cejamericas.org/bitstream/handle/2015/5530/MariaMaltos_Lajusticiares taurativa_REV20.pdf?sequence=1\&isAllowed=y, 2017.

Ministerio de Gobierno de la República de Panamá, \& Fondo de las Naciones Unidas para la Infancia. Marco legal de justicia penal adolescente. Panamá: UNCEF/ MGRP, 2017.

O’Donnell, Daniel. Anuario del XIX Congreso Panamericano del Niño. La Doctrina de la Protección integral y las normas jurídicas vigentes en relación a la familia, (págs. 119161), Monterrey, 2004.

Oficina de las Naciones Unidad contra la Droga y el Delito. Manual sobre Programas de Justicia Restaurativa. Serie de Manuales sobre Justicia Penal. Obtenido de 
Revista Eletrônica de Direito Processual - REDP

Rio de Janeiro. Ano 15. Volume 22. Número 1. Janeiro a Abril de 2021

Periódico Quadrimestral da Pós-Graduação Stricto Sensu em Direito Processual da UERJ

Patrono: José Carlos Barbosa Moreira (in mem.). ISSN 1982-7636. pp. 752-780

www.redp.uerj.br

https://www.unodc.org/documents/justice-and-prison-

reform/Manual_sobre_programas_de_justicia_restaurativa.pdf, 2006.

Organización de las Naciones Unidas \& Comisión de Prevención del Delito. Debate temático

sobre la reforma del sistema de justicia penal: logro de la eficacia y la equidad. Reglas y normas de las Naciones Unidas en materia de prevención del delito y justicia penal.

Obtenido

de

https://www.unodc.org/documents/commissions/CCPCJ/CCPCJ_Sessions/CCPCJ_11/E

-CN15-2002-05-Add1/E-CN15-2002-5-Add1_S.pdf, 2002.

Rangel Buitrago, Sherly Chantal. Ejecución Penal y Medidas de Seguridad. En M. PÚBLICO, CÓDIGO PROCESAL PENAL DE LA REPÚBLICA DE PANAMÁ (COMENTADO), (págs. 320-324), Ciudad de Panamá: Procuraduría General de la Nación, 2018.

SÁNCHEZ GaRCÍA, Arnulfo. ESQUEMAS DE MEDIACIÓN Y ARBITRAJE. Ciudad de México: tirant lo blanch, 2019.

SÁNCHEZ GarCíA, Arnulfo; FernándeZ SiLva, Yulisán. El interés superior del menor en el marco de la utilización de los métodos alternos de solución de conflictos en el ámbito penal. Actualidad jurídica iberoamericana, 2020, no 13. 